\title{
Fatigue design of plated structures using structural hot spot stress approach
}

\author{
M.Heshmati \& M.Al-Emrani \\ Chalmers University of Technology, Gothenburg, Sweden
}

In most fatigue design codes, the nominal stress method is the predominant approach for fatigue design of structures. However, the known limitations of this method along with new advanced computational possibilities, have paved the way to search for more accurate stress based fatigue design approaches. The structural hot spot stress approach (SHSS) is one of these methods which has drawn a wide-spread attention since its advent. The SHSS designates the basic stress by taking into account the geometrical variations of the detail at the location of expected fatigue crack initiation (hot spot). In this paper, the fatigue strength of several frequently used structural details is investigated using both nominal stress and SHSS approaches. The aim of this investigation is to establish an equivalency between these two approaches with reference to the fatigue strengths of the studied details. A large database including available fatigue test results (from 1950s till present) is built up and used to produce hot spot stress S-N curves for the studied details.

\section{INTRODUCTION}

The nominal stress method has been the most widely used fatigue assessment method in the field of structural engineering for decades. This method is generally referred to as the classic fatigue assessment method. The ease of use for versatile structural details and the acceptable accuracy, compared to the work effort, are some advantages of this approach. However, the implementation of more complicated details in steel structures on the one hand, and the increasing demand for more efficient and accurate design methods on the other hand, has caused new limitations for designers to use the nominal stress method. Some of these limitations are remarked in the following paragraphs.

When using nominal stress method, the constructional detail and load type should fall under one of the design classes that are provided by the code. Nevertheless, not all structural details are listed in current fatigue regulations. Thus, in order to obtain a design class for such details, new laboratory tests should be carried out. After performing statistical analysis of the test results, the data can be consolidated into an S-N curve for that detail. This procedure is indeed expensive, time consuming and cumbersome.

Another limitation of nominal stress method is that in more complex structural details, the nominal stress is often affected by various macro geometrical factors which make the task of defining a correct nominal stress very difficult, if not impossible. On the other hand, the growing use of finite element analysis in the new modern design workflow makes it even vaguer to distinguish the nominal stress in the vicinity of the welded joint. This is due to the fact that, finite element analysis, by definition, determines notch stress and not nominal stress. According to Hobbacher (2009), up to now, none of the available codes or guidelines has given explicit instructions of how to determine the nominal stress from $\mathrm{FE}$ results. The methods to determine nominal stress from FE results basically left to the engineering judgment of the designer.

Last but not least, the fatigue life of some details depends on the geometrical properties of the joint such as the length of attachment, transition radius, etc. For such details, IIW or Eurocode 3, usually define several FAT classes for different geometric combinations. The fatigue life, consequently, exhibits a stepwise trend whereas it is, in reality, continues.

All these short comes and limitations make the application of the nominal stress method in some cases complicated, less accurate and less efficient.

The hot spot stress concept was first introduced for the fatigue design of tubular structures decades ago. Over the years, the advantages of this approach compared to the traditional nominal stress method provoked design associations to introduce guidelines and instructions regarding fatigue design of plated 
structures using hot spot stress as well. By definition, the structural hot spot stress approach (SHSS) designates the basic stress, including stress concentration effects caused by geometrical variations of the detail at the expected fatigue crack initiation area (hot spot). SHSS disregards the notch effect caused by the weld profile and comprises all other geometric parameters. Hence, one hot spot stress S-N curve can be associated to several details.

The hot spot stress $\sigma_{\text {Hot spot }}$ can be directly calculated from finite element analysis (FEA) as follows:

$\sigma_{\text {Hot spot }}=K \cdot \sigma_{\text {Nominal }}$

where $\mathrm{K}$ is the structural stress concentration factor derived from the FEA.

The results of several three-dimensional FEA have shown that certain instructions regarding the element types and meshing techniques should be followed in order to obtain comparable results.

In this paper, a large number of fatigue test data of frequently used details in plated steel structures are collected and used to produce nominal stress S-N curves. The results are discussed and compared with the IIW and Eurocode 1993-1-9 recommendations. The FEA instructions given by international welding institute (IIW) are adapted in order to create threedimensional solid models with fine meshes. Both linear and quadratic extrapolation methods are exploited in order to obtain hot spot stress S-N curves. Eventually, an equivalency between these two approaches with reference to the fatigue strengths of the studied details is established.

\section{FATIGUE EVALUATION OF PLATED DETAILS}

\subsection{Longitudinal non-load-carrying attachments}

Longitudinal non-load-carrying attachments are commonly used in many fatigue loaded structures such as ships, cranes, offshore structures and bridges. The universal use of this type of attachment has made it one of the most frequent fatigue tested details. However, although the extensive number of available fatigue tests may facilitate the evaluation of their fatigue strength, these tests might include irrelative and/or unsuitable test data. Therefore, in order to derive any valid conclusions, the test data should be first categorized and filtered. In the current study, after an initial evaluation of the whole available test data, a total number of 286 specimens are selected for further evaluations. In the initial evaluation phase, inappropriate test data such as tests with post-weld treatment, unusual ambient temperatures, negative stress ratios etc. were excluded. Table 1 lists a summary of the approved fatigue test series as depicted in Figure 1.

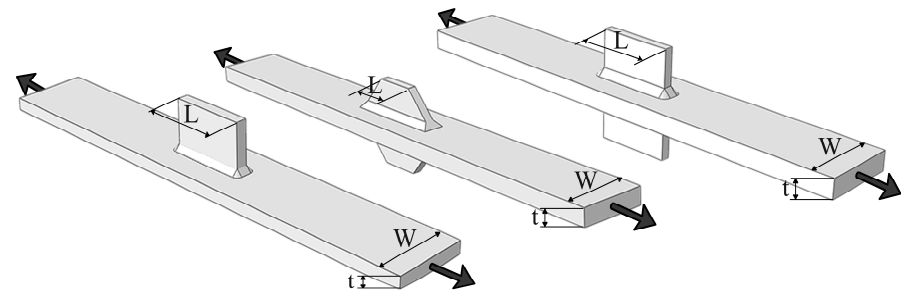

Figure 1. Different Longitudinal attachment test configurations

As the fatigue strength of plates with longitudinal non-load-carrying attachments is known to be a function of the length of the attachment plate, the test results were primarily categorized according to the attachment length, in five different classes.

Table 1. Dimensions and quantity of evaluated fatigue test specimens for longitudinal attachments; all dimensions are in $\mathrm{mm}$.

\begin{tabular}{|c|c|c|c|c|c|}
\hline \multirow{2}{*}{$\begin{array}{l}\text { Attachment } \\
\text { length }\end{array}$} & \multirow{2}{*}{$\begin{array}{l}\text { Test } \\
\text { data }\end{array}$} & \multicolumn{2}{|c|}{ Main Plate } & \multicolumn{2}{|c|}{ Attachment } \\
\hline & & Thicknes & Width & Thickness & Length \\
\hline $\mathrm{L}=200$ & 10 & 4 & 100 & 4 & 200 \\
\hline $\mathrm{L}=150$ & 193 & $4.8-25.4$ & $75-100$ & $4.8-25.4$ & 150 \\
\hline $\mathrm{L}=100$ & 55 & $10-25$ & $80-152.4$ & $10-25$ & 100 \\
\hline $\mathrm{L}=60$ & 11 & 16 & 90 & 16 & 60 \\
\hline$\underline{\mathrm{L}}=50$ & 17 & 8 & 80 & 8 & 50 \\
\hline
\end{tabular}

\subsubsection{Evaluation according to the nominal stress method}

The results from evaluating the test results based on the nominal stress method are presented in Table 2. It is clear that for specimens with attachment plates having a length up to $150 \mathrm{~mm}$, FAT71 seems to provide a good representation for the fatigue strength of the detail. This complies very well with the recommendations in IIW. For test data with $\mathrm{L}=200$, the evaluated fatigue strength at 2 million cycles is below the recommended FAT-category 63. Nevertheless, this category is only composed of one test series in which the main plate is very thin. Therefore, it is anticipated that by including more test data the characteristic value may improve. However, according to the tests evaluated in this study, the recommended FAT class of 63 seems to be unreliable. The test data are plotted in Figure 2.

Table 2. Statistical evaluation of longitudinal attachments test results using linear regression analysis with a fixed slope of 3 .

\begin{tabular}{llll}
\hline Configuration & $\begin{array}{l}\Delta \sigma_{\text {mean }} \\
\mathrm{N} / \mathrm{mm}^{2}\end{array}$ & $\begin{array}{l}\Delta \sigma_{\mathrm{C}} \\
\mathrm{N} / \mathrm{mm}^{2}\end{array}$ & Standard deviation \\
\hline $\mathrm{L}=200$ & 75.4 & 56.9 & 0.157 \\
$\mathrm{~L}=150$ & 88.7 & 75.9 & 0.123 \\
$\mathrm{~L}=100$ & 91.3 & 73.6 & 0.164 \\
$\mathrm{~L}=60$ & 85.8 & 77.9 & 0.056 \\
$\mathrm{~L}=50$ & 88.6 & 77.3 & 0.088
\end{tabular}




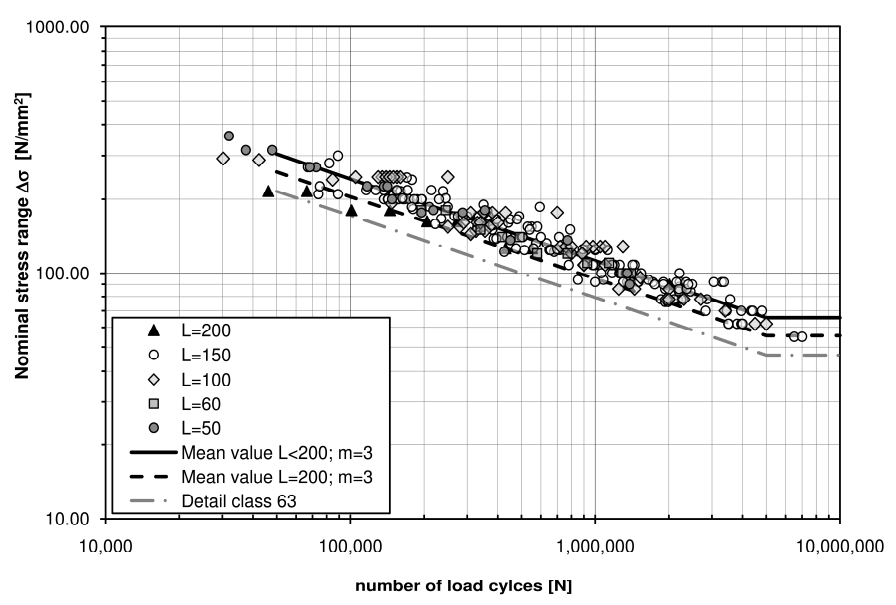

Figure 2. Fatigue test results for longitudinal attachments distinguished by length of attachment

\subsubsection{Evaluation according to the hot spot stress approach}

The collected fatigue test data for this detail dates back to 1950. As a result, a good documentation of the tests is missing in some cases. The weld leg length was one of the parameters that were missing in most of the tests. Therefore, since the whole geometry including the welds had to be modeled, the effect of weld leg length size variation on the stress concentration in the detail was investigated.

The results show that varying the weld leg length from 5 to $15 \mathrm{~mm}$ alters the calculated structural stress concentration factor with less than 5\%. Nevertheless, as recommended by IIW, a minimum weld throat thickness equal to one third of the main plate thickness was assumed where the weld size was unknown.

Moreover, the effect of the main plate width on the fatigue strength of longitudinal attachments is also investigated. As shown in Figure 3, as the main plate becomes wider, the $\mathrm{K}$ factor increases. This effect is more pronounced for plates with the width of 50 to $150 \mathrm{~mm}$. Since most of the tests have a plate width in the mentioned range, it is recommended to consider this parameter as well for evaluation based on the nominal stress method.

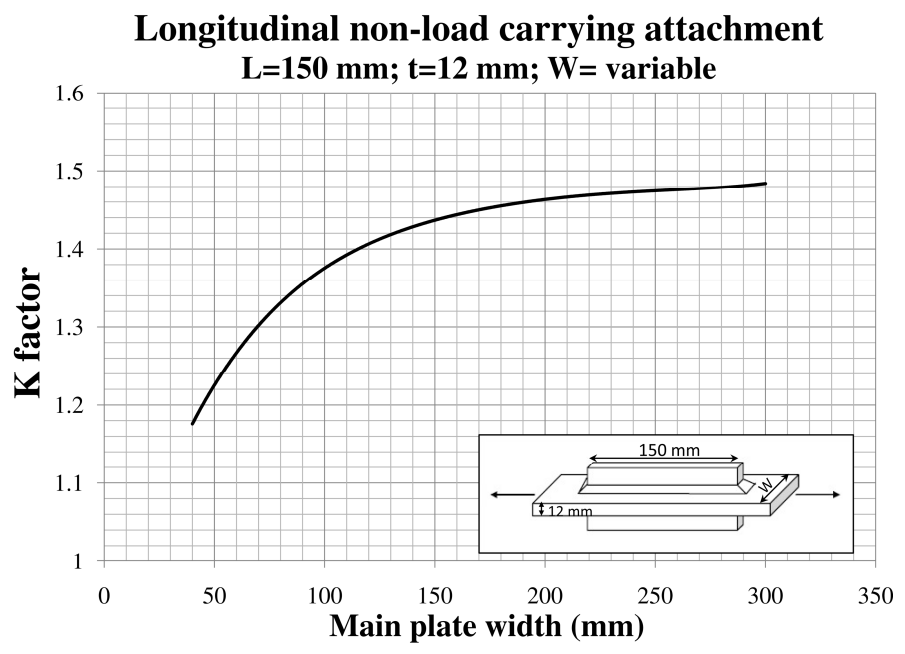

Figure 3. $\mathrm{K}$ factor as a function of main plate width

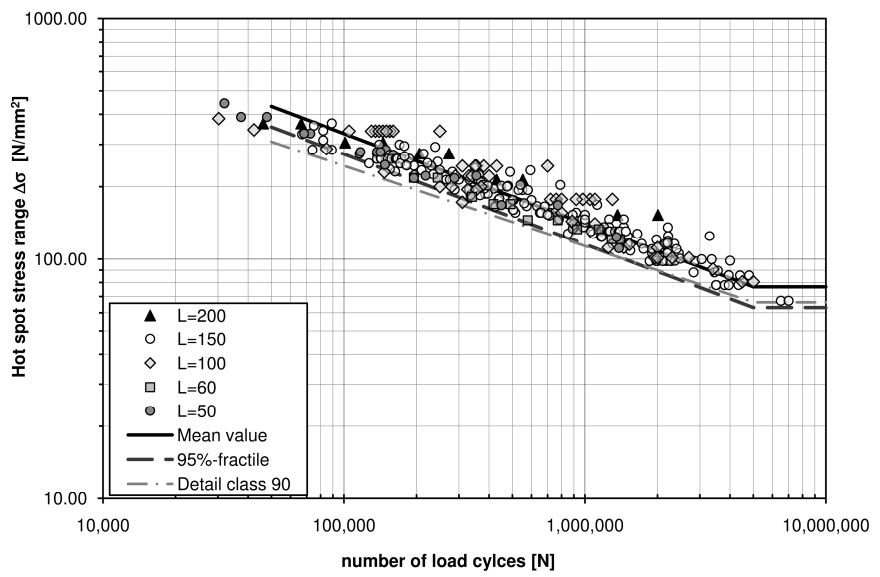

Figure 4. Fatigue test results for longitudinal attachments according to the hot spot stress approach

The test results for the hot spot stress approach are plotted in Figure 8. In this figure quadratic extrapolation of the hot spot stress has been used. The standard deviation is 0.138 and the slope 2.67 evaluated with free linear regression. The characteristic strength is $88.8 \mathrm{MPa}$. With a fixed slope of 3 the standard deviation becomes 0.150 and the characteristic fatigue strength is $94.2 \mathrm{MPa}$. Linear extrapolation was also examined for this detail, giving a standard deviation of 0.150 and characteristic fatigue strength of $93.1 \mathrm{MPa}$. Considering the results in Figure 3 it seems that FAT-category 90 should be used for this detail instead of the FAT100 which is recommended by the IIW.

\subsection{Over-lapped joints with crack at main plate}

Longitudinally loaded over-lapped joints with side welds are usually used in fatigue loaded structures to join different sections to the gusset plate.

The evaluation of fillet welded overlapped joints included 19 test specimens of which 10 failed in the main-plate and 9 in one of the cover-plates. Since the failure types and consequently the hot spot stress evaluation methods are substantially different, the evaluation of this detail is presented separately. Figure 5 demonstrates two different examined test specimens that had failed from the weld toe at the main plate. The geometrical parameters that are considered for this detail are given in Table 3.

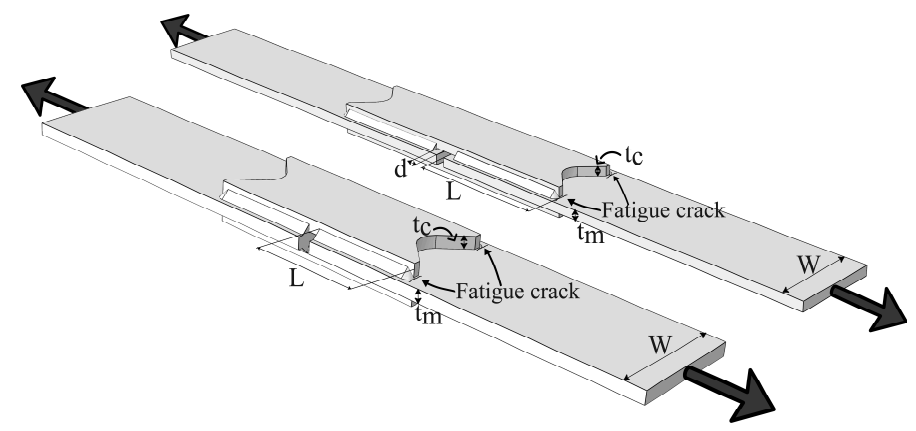

Figure 5. Different configurations of over-lapped joints 
Table 3. Dimensions and quantity of evaluated fatigue test specimens for over-lapped joint with crack at main plate; all dimensions are in $\mathrm{mm}$.

\begin{tabular}{|c|c|c|c|c|c|c|}
\hline \multirow{2}{*}{\multicolumn{2}{|c|}{ Detail Test data }} & \multicolumn{2}{|c|}{ Main plate } & \multicolumn{2}{|c|}{ Cover plate } & \multirow[t]{2}{*}{$\mathrm{d}$} \\
\hline & & $\overline{\mathrm{t}_{\mathrm{m}}}$ & $\mathrm{W}$ & $\mathrm{t}_{\mathrm{c}}$ & $\mathrm{L}$ & \\
\hline$A$ & 5 & 12.7 & 114.3 & 12.7 & 108 & 0 \\
\hline $2 \mathrm{~B}$ & 5 & 12.7 & 114.3 & 12.7 & 171.5 & 12.7 \\
\hline
\end{tabular}

\subsubsection{Evaluation according to the nominal stress method}

As it is shown in Figure 6, the fatigue strength of over-lapped specimens with longer cover plates (2B) is slightly higher than the specimens in series $2 \mathrm{~A}$. The dependency of fatigue life on the weld length has been recognized by Eurocode as well.

Statistical analysis of the test results reveals mean values for the fatigue strength of $73.4 \mathrm{MPa}$ for detail $2 \mathrm{~A}$ and $82.9 \mathrm{MPa}$ for detail $2 \mathrm{~B}$. The characteristic value of all the test data according to the nominal stress method is $61.8 \mathrm{MPa}$ with a standard deviation of 0.135 . The obtained value is consistent with FAT 56 recommended by Eurocode.

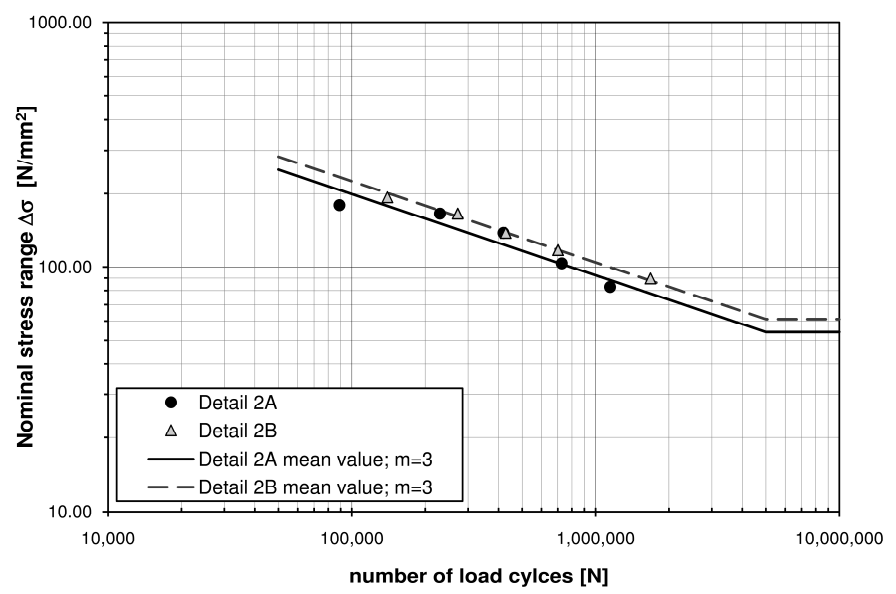

Figure 6. Fatigue test results for over-lapped joints with crack at main plate distinguished by detail type

\subsubsection{Evaluation according to the hot spot stress approach}

The hot spot stress S-N curve for over-lapped joints with crack at main plate are plotted in Figure 7.

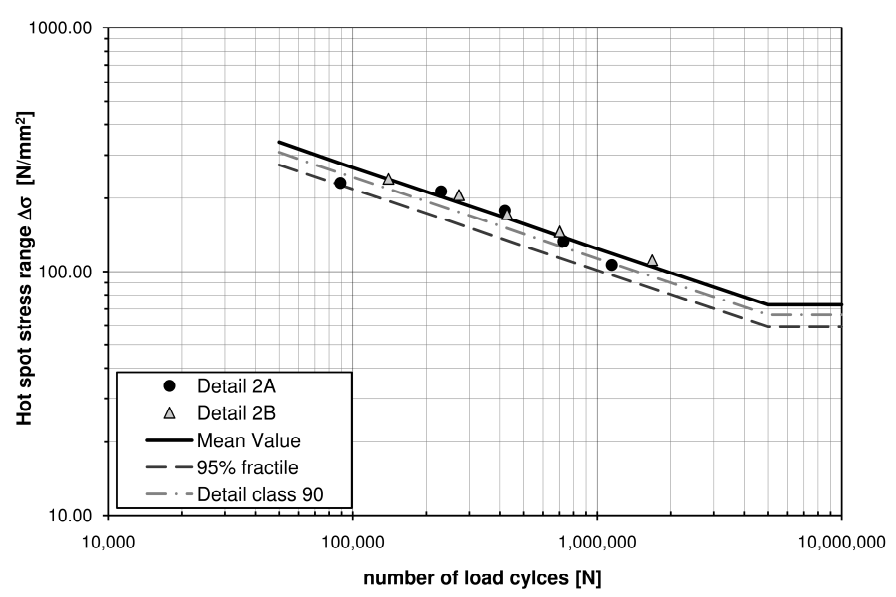

Figure 7. Fatigue test results for over-lapped joints with crack at main plate according to the hot spot stress approach
A linear regression analysis affirms a reduced standard deviation to 0.120 for all the data in this case.

The characteristic value for fatigue strength is 80.3 $\mathrm{MPa}$ which is lower than the recommended FAT100 strength in the IIW. The number of available tests is of course rather limited. Quadratic extrapolation is recommended for this detail as the stress increases very rapidly at the crack initiation point.

\subsection{Over-lapped joints with crack at cover plate}

A total number of 9 over-lapped specimens with cracking in the cover plate are evaluated in this section. The test data includes specimens with two different weld lengths (L). Table 4 lists the quantity and dimensions of the evaluated test data as shown in Figure 8.

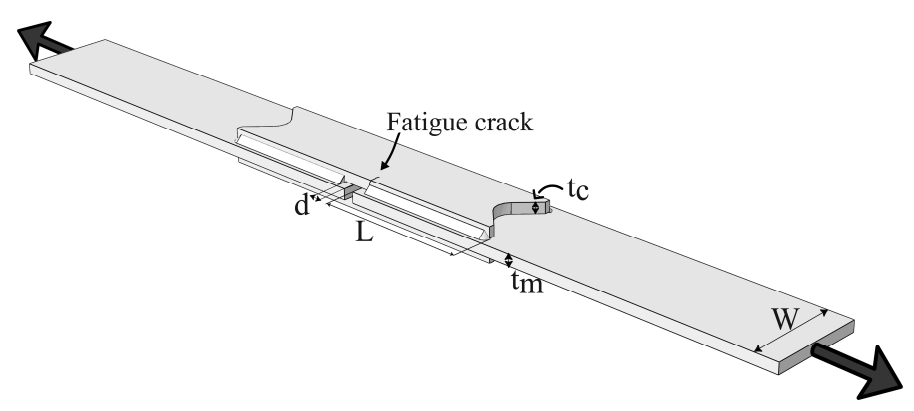

Figure 8. Schematic drawing of over-lapped joints with crack at cover-plate

Table 4. Dimensions and quantity of the evaluated fatigue test specimens for over-lapped joint with crack at cover plate; all dimensions are in $\mathrm{mm}$.

\begin{tabular}{lllllll}
\hline \multirow{2}{*}{ Detail Test data } & & Main plate & \multicolumn{3}{c}{ Cover plate } & \multirow{2}{*}{$\mathrm{d}$} \\
\cline { 2 - 5 } \cline { 5 - 7 } & & $\mathrm{t}_{\mathrm{m}}$ & $\mathrm{W}$ & $\mathrm{t}_{\mathrm{c}}$ & $\mathrm{L}$ & \\
\hline $3 \mathrm{~A}$ & 4 & 12.7 & 114.3 & 9.5 & 95.25 & 0 \\
3B & 5 & 12.7 & 114.3 & 9.5 & 171.5 & 12.7 \\
\hline
\end{tabular}

\subsubsection{Evaluation according to the nominal stress method}

The nominal stress evaluation results for the overlapped joints with crack at cover plate are demonstrated in Figure 9. Similar to the case with crack at main plate, the longer plates exhibit an insignificant higher fatigue life.

The standard deviation when all tests are considered is 0.151 when performing a linear regression analysis with a free slope, giving a mean value of $57.3 \mathrm{MPa}$ and a characteristic value of $46.4 \mathrm{MPa}$. With a fixed slope of 3 , the characteristic value is calculated to $41.1 \mathrm{MPa}$ with a standard deviation increasing to 0.169 . It is worth mentioning that both Eurocode and IIW neglect the plate length effect and recommend design classes 45 and 50 respectively. While the Eurocode recommendation appears to be a good representation, the IIW suggested FAT class 


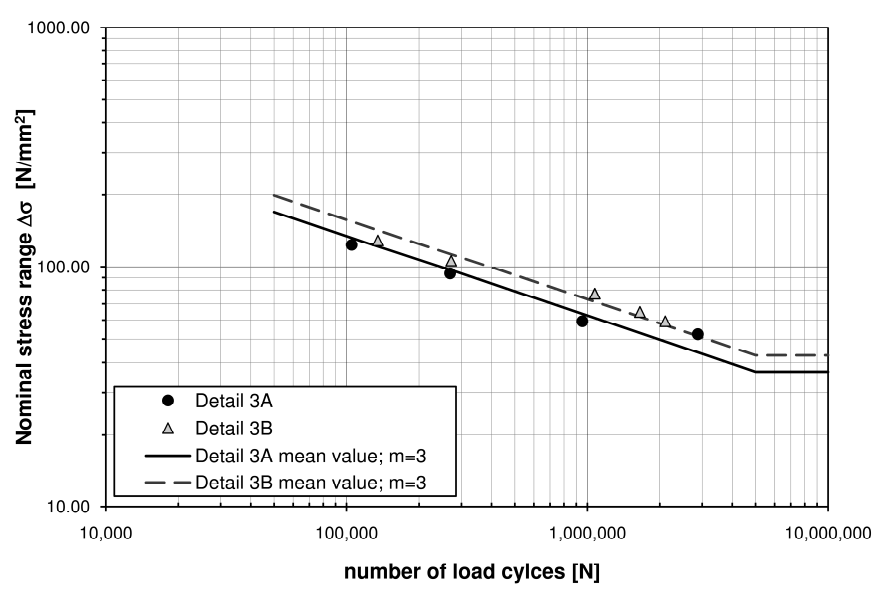

Figure 9. Fatigue test results for over-lapped joints with crack at cover plate distinguished by detail type

seems to be optimistic, when the tests at hand are evaluated.

\subsubsection{Evaluation according to the hot spot stress approach}

As it is shown in Figure 10, the scatter of the test data seems to be reduced when the hot spot stress is used, and the two test groups lie within a narrow scatter band. Linear regression analysis reveals a meaningful reduction of standard deviation to 0.109 when using a free slope. With a fixed slope of 3 the characteristic value becomes $98.9 \mathrm{MPa}$.

According to IIW, the hot spot stress type of this specimen is specified as type b. However, neither IIW nor Eurocode suggest a FAT class base on the hot spot stress for this detail (i.e. for cracking at weld ends). Considering the evaluated tests in this study, FAT100 appears to give good representation. However, more test data on similar details with various configurations of different lengths and thicknesses are needed before a firm conclusion can be made.

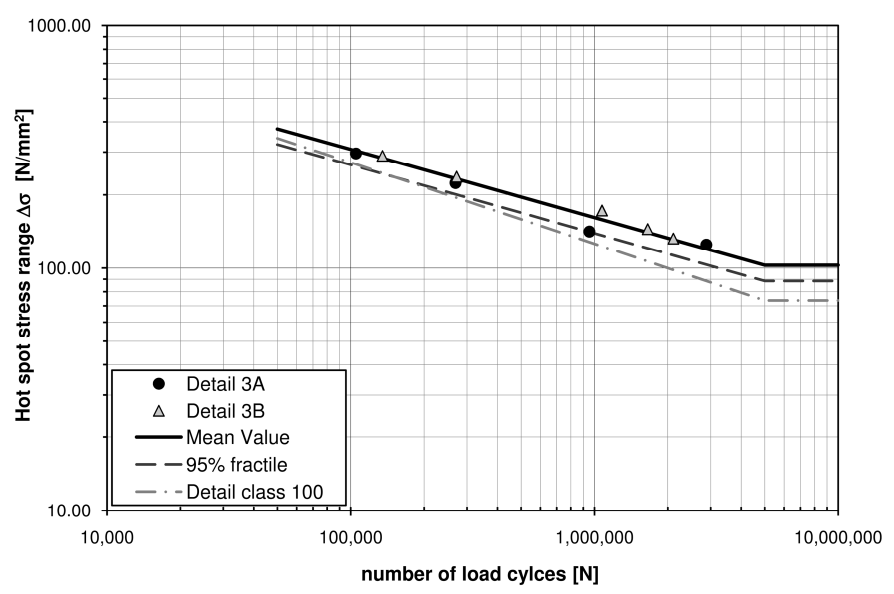

Figure 10. Fatigue test results for over-lapped joints with crack at main plate according to the hot spot stress approach

\subsection{Cope-hole details}

Cope-holes are usually used in field-welded joints in bridge girders to facilitate for the transversal butt welds in the flanges and to avoid weld crossing. The size of the cope-hole is also chosen to give access for the NDT of the butt welds. Constant amplitude fatigue test results of 29 different specimens from 4 different sources have been collected to evaluate this detail. Table 5 represents a detailed overview of various test configurations as illustrated in Figure 11.

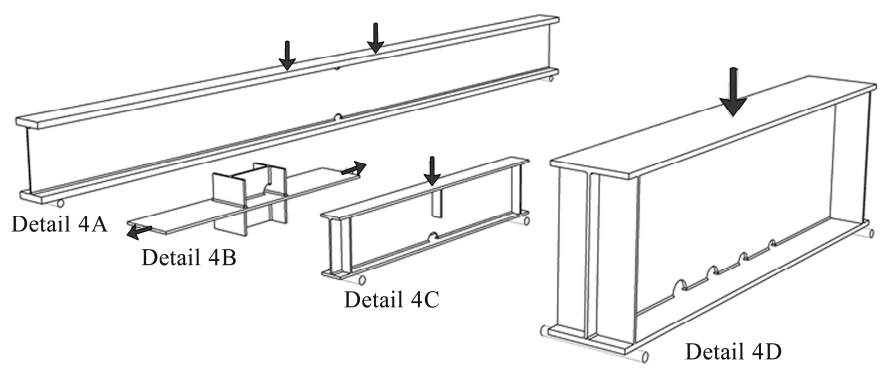

Figure 11. Different cope-hole test configurations

Table 5. Dimensions and quantity of the evaluated fatigue test specimens for cope-holes; all dimensions are in $\mathrm{mm}$.

\begin{tabular}{|c|c|c|c|c|c|c|}
\hline \multirow[t]{2}{*}{$\overline{\text { Detail }}$} & \multirow[t]{2}{*}{ Test data } & \multicolumn{2}{|l|}{ Main plate } & \multicolumn{2}{|l|}{ Attachment } & \multirow[t]{2}{*}{$\tau_{\mathrm{a}} / \sigma_{\mathrm{m}}$} \\
\hline & & Thickness & Width & Thickness & Radius & \\
\hline$\overline{4 \mathrm{~A}}$ & 7 & 25.4 & 127 & 4.8 & 25.4 & 0 \\
\hline 4B & 8 & 9 & 200 & 9 & 35 & 0 \\
\hline $4 \mathrm{C}$ & 7 & 8 & 80 & 6 & 26 & 0.2 \\
\hline 4D & 7 & 16 & 250 & 9 & $25-40$ & $0.7-1$ \\
\hline
\end{tabular}

\subsubsection{Evaluation according to the nominal stress method}

As listed in Table 6, the fatigue strength of the evaluated cope-hole details is very inconsistent. A closer look at the results in Figure 12 reveals that despite the conspicuous geometrical variation of details $4 \mathrm{~A}$ and $4 \mathrm{~B}$, they exhibit almost identical fatigue strength. However, detail 4D which is more similar to $4 \mathrm{~A}$ shows a dramatic fall in terms of fatigue strength. A more thorough assessment of the tests, reveals a pronounced dependency of fatigue life of cope-hole details on the ratio of shear stress to normal stress in the specimens $\left(\tau_{\mathrm{a}} / \sigma_{\mathrm{m}}\right)$, see Figure 12 . It is clear that the relatively low fatigue strength of details in the test series 4D is due to the presence of considerable shear stresses at the anticipated crack location i.e. weld toe at cope-hole section. The destructive effect of shear stresses on the fatigue life of cope-hole details has been previously confirmed by Miki \& Tateishi (1997). Therefore, evaluation of the test results, based on the nominal stress in these details, should consider the ratio $\tau_{\mathrm{a}} / \sigma_{\mathrm{m}}$ as an important parameter that affects the fatigue strength of copehole details. While this has been recognized in IIW, the Eurocode 1993-1-9 assigns detail category 71 to cope-hole details irrespective of the ratio $\tau_{\mathrm{a}} / \sigma_{\mathrm{m}}$. 


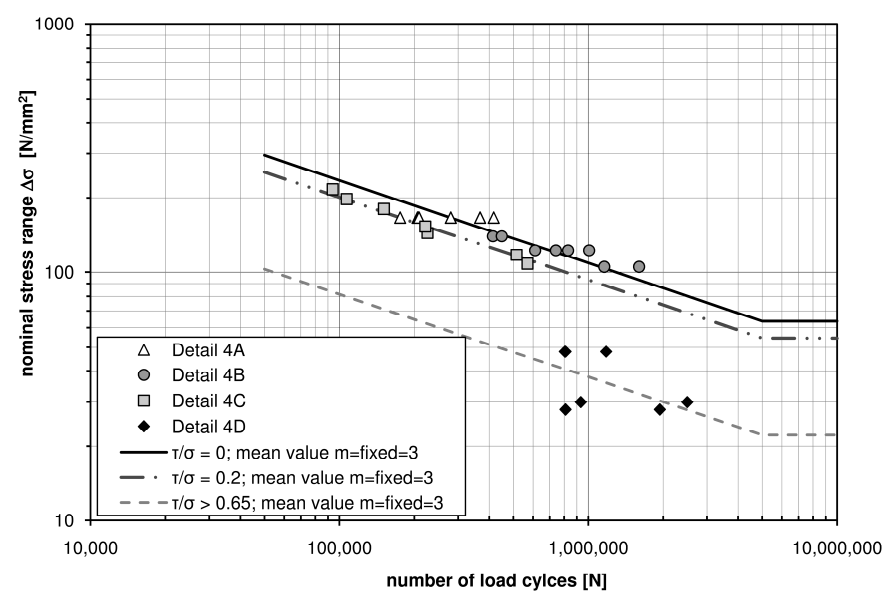

Figure 12. Fatigue test results for cope-hole details distinguished by shear to normal stress ratio

Table 6. Statistical evaluation of the cope-hole test results using linear regression analysis with a fixed slope of 3.

\begin{tabular}{llll}
\hline Type of joint & $\Delta \sigma_{\text {mean }}$ & $\Delta \sigma_{\mathrm{C}}$ & Standard deviation \\
& $\mathrm{N} / \mathrm{mm}^{2}$ & $\mathrm{~N} / \mathrm{mm}^{2}$ & \\
\hline Detail 4A* & 83.8 & -- & -- \\
Detail 4B & 88.9 & 71.9 & 0.093 \\
Detail 4C & 74 & 64.7 & 0.055 \\
Detail 4D & 30 & 16.7 & 0.345 \\
\hline
\end{tabular}

* Since all the specimens were tested in one stress range, a statistical evaluation is not possible.

\subsubsection{Evaluation according to the hot spot stress approach}

The test results of all cope-hole details evaluated based on the hot spot stresses are plotted in Figure 13. It is apparent that although the test data do not lie in one group, the scatter of the results, compared to the nominal stress method, is decreased. Linear regression analysis with a fixed slope of 3 gives a standard deviation of 0,281 compared with the value of 0.614 obtained from the nominal stress method. However, the calculated characteristic fatigue strength of $70.6 \mathrm{MPa}$ is considerably lower than what is specified in IIW and Eurocode (FAT100). If the results from detail 4D which undergoes the highest $\tau_{\mathrm{a}} / \sigma_{\mathrm{m}}$ ratio are excluded, FAT100 appears to be a reasonable representation. The low hot spot stress value obtained for detail 4D is assumed to be because of the presence of high amount of shear stresses in the web which causes the weld to become load carrying. In such a case, the weld at the copehole transfers the existing shear stresses in addition to the normal stresses caused by the bending of the beam.

Thus, in order to account for such severe loading conditions, it is recommended to apply a further reduction of design class to FAT90 for cope-holes in beams when using the hot spot stress approach.

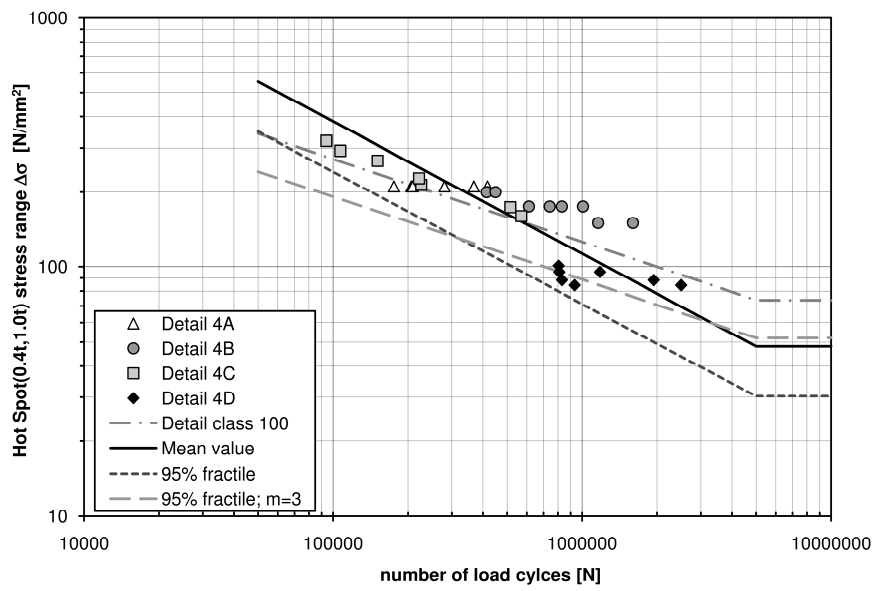

Figure 13. Fatigue test results for cope-hole details according to the hot spot stress approach

It is noteworthy that for Detail $4 \mathrm{C}$, surface stress extrapolation according to IIW recommendation was not feasible due to the small radius of the cope-hole in relation to the flange thickness. Therefore, the hot spot stress was calculated as $1.12 \cdot 0.5 \mathrm{t}$ according to Lotsberg \& Sigurdsson (2006). Moreover, In order to calculate the hotspot stress concentration factor, the nominal stress for beam specimens is calculated as the stress in the mid section of the cope hole using the net cross section and the simple beam theory formula.

\subsection{Cover-plates on beams}

Partial-length Cover-Plates are usually welded to the flanges of steel bridge girders in order to increase the moment capacity and consequently the allowable traffic load and span of the bridge. For this detail, constant amplitude fatigue test results of 183 coverplate specimens have been evaluated. The specimens accommodate a wide range of geometric variations such as the cover-plate to main plate thickness ratio $\left(t_{c} / t_{m}\right)$ and the cover-plate end shape; see Figure 14 and Table 7.

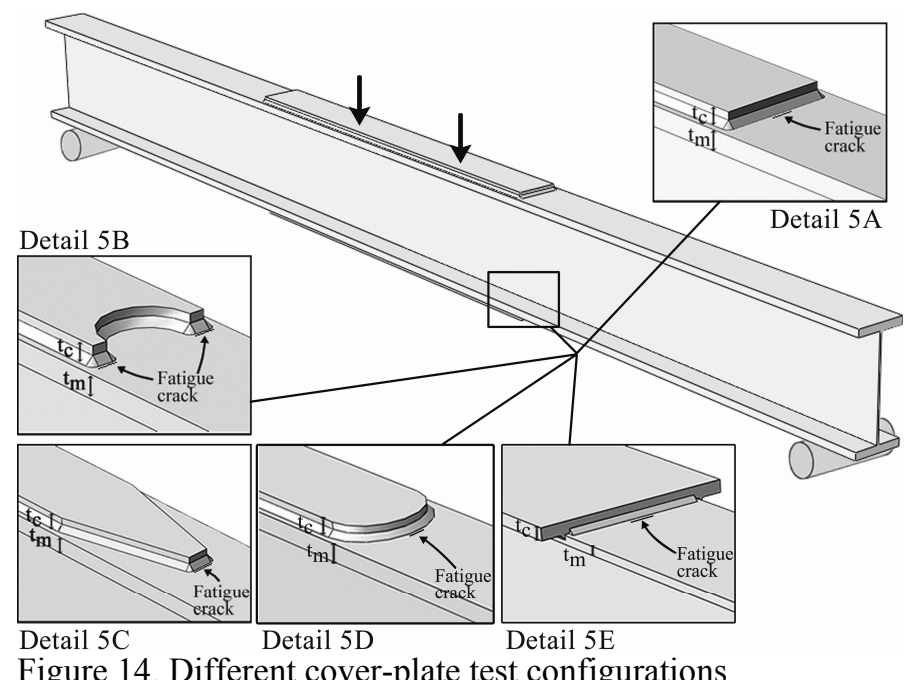

Figure 14. Different cover-plate test configurations 
Table 7. Dimensions and quantity of the evaluated fatigue test specimens for cover-plates; all dimensions are in $\mathrm{mm}$.

\begin{tabular}{|c|c|c|c|c|c|c|}
\hline \multirow[t]{2}{*}{ Detail } & \multirow[t]{2}{*}{ Test data } & \multicolumn{2}{|l|}{ Main plate } & \multicolumn{2}{|c|}{ Cover plate } & \multirow[t]{2}{*}{$\mathrm{t}_{\mathrm{c}} / \mathrm{t}_{\mathrm{m}}$} \\
\hline & & Thickness & Width & Thickness & Width & \\
\hline$\overline{5 \mathrm{~A} 1}$ & 30 & 9.525 & 171 & 19.05 & 114 & 2 \\
\hline $5 \mathrm{~A} 2$ & 102 & 9.525 & 171 & 14.3 & 114 & 1.5 \\
\hline $5 \mathrm{~A} 3$ & 5 & 19.05 & 127 & 12.7 & 101.6 & 0.67 \\
\hline $5 B$ & 5 & 19.05 & 127 & 12.7 & 101.6 & 0.67 \\
\hline $5 \mathrm{C}$ & 6 & 19.05 & 127 & 12.7 & 101.6 & 0.67 \\
\hline 5D & 5 & 19.05 & 127 & 12.7 & 101.6 & 0.67 \\
\hline $5 \mathrm{E}$ & 30 & 9.525 & 171 & 14.3 & 229 & 1.5 \\
\hline
\end{tabular}

\subsubsection{Evaluation according to the nominal stress method}

Conforming to the data shown in figure 15 and Table 8 , the fatigue strength of cover plates seems to be particularly affected by the ratio $t_{\mathrm{c}} / \mathrm{t}_{\mathrm{m}}$. It is apparent that cover plates with the lowest $t_{\mathrm{c}} / \mathrm{t}_{\mathrm{m}}$ ratio exhibit the highest fatigue strength. However, this effect disappears for details with $t_{\mathrm{c}} / \mathrm{t}_{\mathrm{m}}>1$. These details demonstrate the same fatigue strength. Moreover, as the fatigue test results of cover plates with various end shapes lie latently within the same scatter band, it can be concluded that changing the cover plate end shape does not affect the fatigue strength of cover plate details.

While Eurocode has limited the effect of $t_{\mathrm{c}} / \mathrm{t}_{\mathrm{m}}$ to ratios only less than and higher than one, IIW considers several intervals. Consequently, considering the evaluated data in this study, Eurocode recommendations appear to be more consistent.

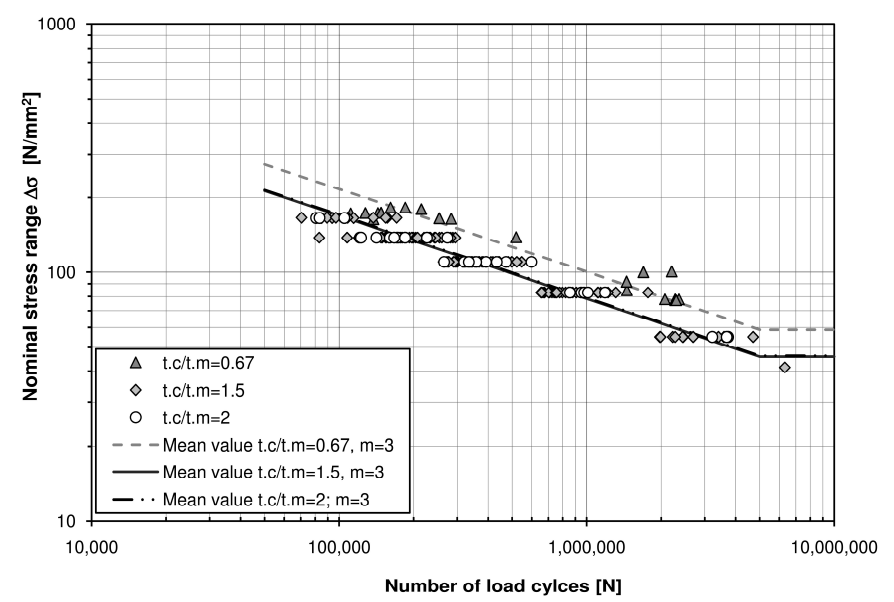

Figure 15. Fatigue test results for cover-plate details categorized by cover plate to main plate thickness ratio

Table 8: Statistical evaluation of the cover-plate test results using linear regression analysis with a fixed slope of 3.

\begin{tabular}{lllll}
\hline \multicolumn{2}{c}{ Configuration Test Data } & $\begin{array}{l}\Delta \sigma_{\text {mean }} \\
\mathrm{N} / \mathrm{mm}^{2}\end{array}$ & $\begin{array}{l}\Delta \sigma_{\mathrm{C}} \\
\mathrm{N} / \mathrm{mm}^{2}\end{array}$ & $\begin{array}{l}\text { Standard devia- } \\
\text { tion }\end{array}$ \\
\hline $\mathrm{t}_{\mathrm{c}} / \mathrm{t}_{\mathrm{m}}=0.67$ & 21 & 79.7 & 64.8 & 0.147 \\
$\mathrm{t}_{\mathrm{c}} / \mathrm{t}_{\mathrm{m}}=1.5$ & 132 & 62.2 & 54.4 & 0.104 \\
$\mathrm{t}_{\mathrm{c}} / \mathrm{t}_{\mathrm{m}}=2$ & 30 & 62.7 & 54.3 & 0.103 \\
\hline
\end{tabular}

\subsubsection{Evaluation according to the hot spot stress approach}

The test results of all cover-plate details are shown in Figure 13. As it was expected, the geometrical effects of different shapes and configurations are implicitly accounted for by the hot spot stress approach and all the data lie within one scatter band. This observation is supported by the statistical analysis as well. The standard deviation of all test data decreases significantly from 0.149 in the nominal stress approach to 0.116 for the hot spot stress approach. The recommended FAT100 seems also to be a reasonable representation for the fatigue strength of this detail.

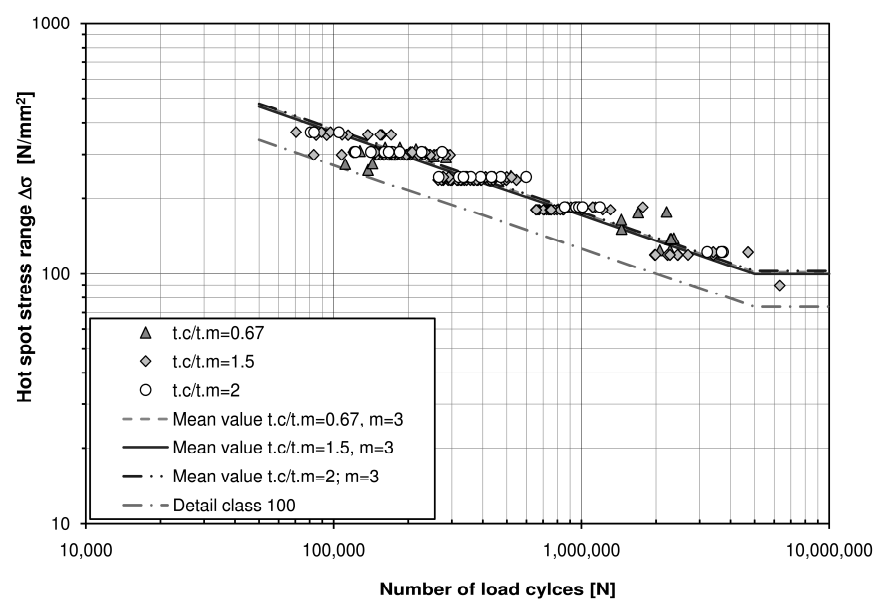

Figure 13. Fatigue test results for cover-plate details according to the hot spot stress approach

\section{CONCLUSIONS}

The following conclusions can be drawn:

- The hot spot stress method is capable of reducing the scatter caused by the geometrical variations. As a result, one hot spot stress S-N curve can be associated to several details.

- For longitudinal non-load-carrying attachments, the design recommendations according to IIW based on the nominal stress method appears to be consistent with the available test data. However, the recommended FAT100 for evaluation based on the hot spot stress approach seems to be inconservative and should be replaced by FAT90.

- For evaluation of details with load carrying welds based on the hot spot stress approach, a further reduction of the suggested design class FAT90 to FAT80 is recommended based on the evaluated tests. This reduction is relevant for overlapped joints with crack at main plate.

- Quadratic extrapolation is recommended for longitudinally loaded overlapped joints with crack at main plate.

- According to the evaluated test data for overlapped joints with crack at cover plate, FAT100 is 
recommended for type $\mathrm{b}$ cracks at cover plates when using hot spots stress approach.

- The ratio of the shear stress to the normal bending stress $\left(\tau_{\mathrm{a}} / \sigma_{\mathrm{m}}\right)$ in cope-hole details seems to effect the fatigue strength of these details considerably. This ratio should be considered by the designer when the fatigue design is made based on the nominal stress method.

- FAT90 is recommended for cope-hole details undergoing $\tau_{\mathrm{a}} / \sigma_{\mathrm{m}} \leq 0.2$ according to the hot spot stress approach.

- Altering the shape of cover-plates end does not affect the fatigue strength.

- The suggested FAT100 seems to be a reasonable representation for the design of cover-plates based on the hot spot stress method.

\section{ACKNOWLEDGEMENT}

The work presented in this paper is a part of the research project Brifag - Bridge Fatigue Guidance with a financial grant from the Research Fund for Coal and Steel (contract No. RFSRCT-2008-00033) as well as the Swedish Transport Administration.

\section{REFERENCES}

European standard, 2005. Eurocode 3: Design of steel structures - Part 1-9: Fatigue, Brussels: European Committee for Standardization

Fisher, J.W. et al. 1969. Effect of weldments on the fatigue strength of steel beams. Fritz engineering laboratory report No.334.2

Fricke, W. 2001. Recommended hot spot analysis procedure for structural details of FPSO's and ships based on roundrobin FE analysis. Int. 7 Offshore Polar Eng., 12(1)

Gurney, T.R. et al. 1961. Influence of artificially induced residual stresses on Fatigue strength of load carrying fillet welded joints in mild steel. British welding journal, 541553

Hall, L.R \& Stallmeyer, J.E. 1959. The fatigue strength of flexural members. Fatigue committee - welding research council.

Hobbacher, A. 2008. IIW document IIW-1823-07 ex XIII2151r4-07/XV-1254r4-07

Hobbacher, A.F. 2009. The new IIW recommendations for fatigue assessment of welded joints and components: A comprehensive code recently updated. International journal of fatigue 31:50-58

Izdinsky, O. et al. 1958. Engine room section in the building of river ships and the welding of steel reinforcements to the bottom cover ship. ZVARANIE VII/12: 363-368

Lotsberg, I. \& Sigurdsson, G., 2006. Hot Spot Stress S-N Curve for Fatigue Analysis of Plated Structures. Journal of Offshore Mechanics and Arctic Engineering,128(4):330336.

Miki, C. \& Tateishi, K. 1997. Fatigue strength of cope-hole details in steel bridges. International journal of fatigue Vol. 19 No.6: 445-455
Stallmeyer, J.E. et al. 1957. Behaviour of welded built-up beams under repeated loads. Structural research series No.135

Xiao, Z. \& Yamada, K. 2005. Fatigue strength of intersecting attachments. Journal of structural engineeringACSE: 924932 